\title{
SCIDOC
}

\author{
International Journal of Dentistry and Oral Science (IJDOS) \\ ISSN: 2377-8075
}

\section{Comparision of Salivary CXCL10 Levels In Smokers and Non-Smokers With Stage III / IV Generalized Periodontal Disease}

Research Article

Arya Mitra Loka ${ }^{1 *}$, Deepa Ponnaiyan² ${ }^{2}$ Harinath. $\mathrm{P}^{2}$

${ }^{1}$ Post Graduate Student, Department of Periodontics, SRM Dental College, Ramapuram, Chennai, India.

${ }^{2}$ Professor, Department of Periodontics, SRM Dental College, Ramapuram, Chennai, India.

\section{Abstract}

\begin{abstract}
Aim: The aim of this study was to compare salivary CXCL10 levels with stage III and IV generalized periodontitis in smokers and non-smokers.

Patients and Methods: Subjects were classified as stage III and/or IV generalized periodontitis subjects, if they had pocket probing depth (PD) of $\geq 6 \mathrm{~mm}$ and/or clinical attachment level (CAL) of $\geq 5 \mathrm{~mm}$ in $>30 \%$ of the teeth, tooth loss of $\leq 4$ teeth, radiological bone loss extending to the middle third of root and beyond and vertical bone loss of $\geq 3 \mathrm{~mm}$. 84 subjects were recruited in this study, Group I consists of 42 non-smoker subjects with stage III and/ or stage IV generalized periodontitis and Group II consists of 42 smoker subjects with stage III and/ or stage IV generalized periodontitis. ELISA analysis was performed to determine the salivary CXCL10 levels.

Statistics analysis: A student t-test was used to compare continuous variables between two groups and Pearson's correlation test was used to correlate CXCL10 with clinical parameters for both the groups. A p-value of $<0.05$ was considered statistically significant.

Results: Clinical parameters in both the groups were positively correlated with CXCL10 levels and higher concentrations of CXCL10 were found in group II subjects as compared with the group I subjects ( $255 \pm 193.7$ and $84 \pm 35.8, P \leq 0.005)$.

Conclusion: Smoking influences salivary CXCL10 levels in stage III and/or IV generalized periodontitis subjects.
\end{abstract}

Keywords: CXCL10; Periodontal Disease; Smoking; Biomarker And Saliva.

\section{Introduction}

Periodontitis is a chronic irreversible inflammatory disease of supporting tissues of teeth caused by microorganisms [1], systemic diseases like coronary heart disease [2], diabetes mellitus [3], atherosclerosis and other risk factors like obesity [3], smoking [4], poor oral hygiene, stress, and depression [5] destroying alveolar bone loss with increased pocket probing depth, clinical attachment loss, and gingival recession. Smoking is considered as a significant risk factor for periodontitis as smokers are five times more prone to develop periodontitis [6]. smoking cessation has been shown to slow the progression of periodontal disease [7-9]. Smoking increases the risk of periodontitis by elevating colonization of periodontal pathogens [10], alters immune-inflammatory response elevating inflammatory mediators like NFx , PGE2, neutrophil elastase, and MMP-8 $[11,12]$. In periodontitis elevated levels of inflammatory cytokines, chemokines, and other media- tors like interleukin (IL)-1 $\beta$, IL-6, IL-10, IL-12, interferon (IFN)- $\gamma$ induced protein (IP)-10 or CXCL10 are elevated.

Based on chemical structure, chemokines are divided into two families: CXC and CC and their receptors are CXCR and CCR [13], they are further classified into C, CC, CX3C, and CXC subgroups. CXCL10 is a pro-inflammatory cytokine that is secreted by various cells like PMN, keratinocytes, fibroblasts, endothelial cells, monocytes [14-18]. IFN- $\gamma$ binds to the IFN- $\gamma$ receptor and activates the JAK-STAT pathway which leads to activation of CXCL10 transcription [19]. CXCL10 binds to the CXCR3 receptor which is present on Th1 cells, cytotoxic cells, and natural killer cells and triggers immune response at the site of infection as well as increases lymphocyte chemotaxis, thus elevating inflammatory response [20-22]. CXCL10 is an established biomarker in cardiac diseases like left ventricular dysfunction [23, 24]. Studies confirmed that CXCL10 contributes to bone resorption in dis-

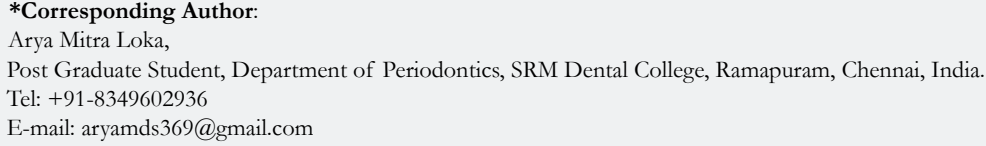

Citation: Arya Mitra Loka, Deepa Ponnaiyan, Harinath. P. Comparision of Salivary CXCL10 Levels In Smokers and Non-Smokers With Stage III/IV Generalized Periodontal Disease. Int J Dentistry Oral Sci. 2021;8(8):4032-4035. doi: http://dx.doi.org/10.19070/2377-8075-21000823

Copyright: Arya Mitra Loka ${ }^{\circ}$ 2021. This is an open-access article distributed under the terms of the Creative Commons Attribution License, which permits unrestricted use, distribution and reproduction in any medium, provided the original author and source are credited. 
eases like rheumatoid arthritis [25-27]. Recently CXCL10 has received considerable attention as a biomarker for periodontal diseases owing to its influence on osteoclastogenesis [28]. Studies in CXCL10 in serum, saliva, and GCF have shown that CXCL10 levels are higher in periodontal diseased compared to healthy and concluded that CXCL10 can serve as a biomarker in periodontitis [29-31]. Further CXCL10 was studied in the saliva of smokers compared with non-smokers and it was found that smokers had higher levels than non-smokers. However, this finding was observed in a limited sample size, the findings cannot be conclusive. Therefore, the effects of smoking on CXCL10 chemokine levels in periodontal disease needs further clarification. This will help to understand the effect of smoking on CXCL10 levels. Although, CXCL10 levels have been evaluated in smokers and non-smokers of the periodontitis group but owing to the small smoker sample size definitive results couldn't be obtained. Thus, the aim of the present study was to detect and quantify the salivary levels of CXCL10 in smokers and non-smokers and also to check the correlation of the clinical parameters with CXCL10 in stage III or IV generalized periodontitis subjects.

\section{Materials and Methods}

A total of 84 individuals were recruited by convenience sampling from the outpatient clinic of SRM Dental College and Hospital, Ramapuram, Chennai. They were categorized into two groups. Group I comprising of 42 stage III/IV Generalized periodontitis non-smokers subjects, Group II comprising of stage III/IV Generalized periodontitis smokers subjects. The study period for recruitment of people and sample collection was from December 2019 till February 2020. Before sample collection, Informed consent was obtained from all the subjects.

Inclusion criteria include 84 systematically healthy subjects of both genders with an age range of 20 to 50 years and patients with no drug history of immunosuppressants, anti-inflammatory, antibiotics also patients who didn't undergo any periodontal treatment during the past 3 months were included during this study. Sample size calculation was calculated from Aldahlawi s et al study with 80 percent power and 5\% alpha error.

Age, gender, smoking habits, and clinical periodontal examination were assessed by one skilled examiner. Clinical parameters like pocket probing depth (PD) and clinical attachment loss (CAL) were calculated on all 6 sites per tooth (mesiobuccal, mid buccal, distobuccal, distolingual, mid lingual, and mesiolingual) with a UNC-15 probe and also Plaque index [32] and Gingival index [33] were recorded for 4 surfaces of all the teeth (mesial, distal, lingual or palatal, and labial or buccal). The diagnosis was made consistent with clinical parameters and radiographic evaluation proposed by the American Academy of Periodontology (AAP) in 2017 [34]. Both the groups include stage III and IV generalized periodontitis subjects. In group 2 current smokers were recruited as per CDC classification. Subjects with a history of periodontal therapy within the last 3 months, intake of antibiotics, immunosuppressants, and anti inflammatory drugs for the past 3 months, pregnant or lactating females, former smokers, and presence of any systemic disease were excluded from participating during this study. Patients were instructed to not take any food or liquids 2 hours before saliva sample collection. Before collection of saliva, patients were instructed to rinse their mouth with water, after which unstimulated whole mixed saliva was collected during a sterile container by spitting method [35]. After collection, saliva samples were centrifuged at $3000 \mathrm{rpm}$ for $10 \mathrm{~min}$ and therefore the supernatant was stored at $-80^{\circ} \mathrm{C}$ until further analysis. ELISA analysis - the amount of CXCL10 was analyzed in saliva employing a commercial ELISA kit (Raybiotech, GA, US). Standard solutions were prepared and diluted as per the manufacturer's instruction. Samples were added to CXCL10 coated wells and analysis was performed as per manufacturers instruction and absorbance values were determined by an ELISA Reader in picogram/milliliter values. All statistical analysis was performed using SPSS version 17 for Microsoft Windows. the data were expressed as Mean $\pm \mathrm{SD}$. An Independent sample student t-test was used to compare continuous variables between two groups. Pearson's correlation test was used to correlate CXCL10 with clinical parameters for both groups. A p-value of $<0.05$ was considered statistically significant.

\section{Results}

A total of 84 subjects including both males and females were recruited in the study with a mean of 35 years \pm 7.1 (range 20-50 years). In group I there was female predominance with 24 females and 16 male subjects and group II consists of 42 male smokers with mean of $34.7 \pm 6.8$ years.

Comparison of clinical parameters and CXCL10 between groups are shown in table 1, allperiodontal clinical parameters were highly significant. Comparison of CXCL10 levels in both the groups are shown in graph 1.

Spearman's rank correlation was performed to analyze the associations between the CXCL10 levels with clinical parameters (PD, CAL, PI and CI) in both the groups are shown in table 2 and table 3 .

\section{Discussion}

CXCL10, an inflammatory chemokine plays a role in periodontal bone remodelling under pathological conditions [13]. In osteoclast precursors, CXCL10 induces osteoclast differentiation, which helps to bind RANK to RANKL and contributes to bone resorption [36]. Further, it also upregulates alkaline phosphatase

Graph 1. Represents CXCL10 or IP-10 levels in both the groups.

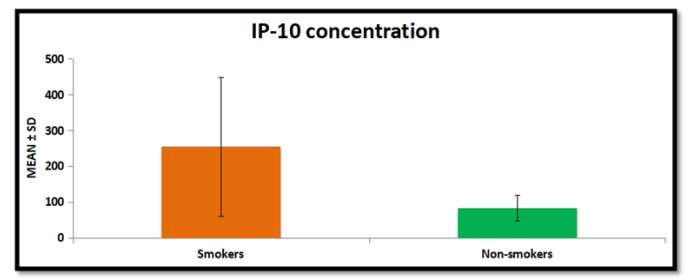


Table 1. Comparison of clinical parameters and CXCL10 between group I and group II.

\begin{tabular}{|c|c|c|c|}
\hline $\begin{array}{c}\text { Clinical parame- } \\
\text { ters and } \\
\text { CXCL10 values }\end{array}$ & $\begin{array}{c}\text { Group I (generalized periodonti- } \\
\text { tis non-smokers) } \mathbf{n}=\mathbf{4 2} \\
\text { Mean and SD }\end{array}$ & $\begin{array}{c}\text { Group II (generalized periodontitis } \\
\text { smokers) } \mathbf{n}=\mathbf{4 2} \\
\text { Mean and SD }\end{array}$ & p value \\
\hline GI & $2.2 \pm 0.1$ & $2.1 \pm 0.2$ & 0.127 \\
\hline PI & $2 \pm 0.1$ & $2.2 \pm 0.1$ & $.000^{* *}$ \\
\hline PPD & $4.2 \pm 0.4$ & $4.5 \pm 0.5$ & 0.015 \\
\hline CAL & $4.3 \pm 0.4$ & $4.7 \pm 0.7$ & $.004^{* *}$ \\
\hline CXCL10 & $84 \pm 35.8$ & $255 \pm 193.7$ & $.000^{* *}$ \\
\hline
\end{tabular}

${ }^{* *} \mathrm{p}<0.05$ is significant, ${ }^{* * \mathrm{p}}<0.005$ is very significant, $\mathrm{GI}=$ Gingival index, $\mathrm{PI}=$ Plaque index, $\mathrm{CAL}=$ Clinical attachment loss, $\mathrm{PPD}=$ Pocket probing depth, cxcl10

Table 2. Correlation of clinical parameters with CXCL10 levels in group I generalized periodontitis non-smokers. GI= Gingival index, PI= Plaque index, CAL= Clinical attachment loss, PPD= Pocket probing depth.

\begin{tabular}{|c|c|c|c|c|}
\hline Correlation of CXCL10 & GI & PI & PD & CAL \\
\hline $\begin{array}{c}\text { CXCL10 } \\
\text { Pearson coefficient }(\mathrm{r})\end{array}$ & $.376^{*}$ & $.414^{* *}$ & $.815^{* *}$ & $.824^{* *}$ \\
\hline p value & 0.05 & 0.01 & 0.01 & $.01^{*}$ \\
\hline
\end{tabular}

**Correlation is significant at 0.01 leve

* Correlation is significant at 0.05 level

Table 3. Correlation of clinical parameters with CXCL10 levels in group II generalized periodontitis smokers. GI $=$ Gingival index, PI= Plaque index, $\mathrm{CAL}=\mathrm{Clinical}$ attachment loss, $\mathrm{PPD}=\mathrm{Pocket}$ probing depth.

\begin{tabular}{|c|c|c|c|c|}
\hline Correlation of CXCL10 & GI & PI & PD & CAL \\
\hline $\begin{array}{c}\text { CXCL10 } \\
\text { Pearson coefficient }(\mathrm{r})\end{array}$ & $.761 *$ & $.749 * *$ & $.962^{* *}$ & $.954^{* *}$ \\
\hline p value & 0.01 & 0.01 & 0.01 & $.01 *$ \\
\hline & $* *$ Correlation is significant at 0.01 level \\
& Correlation is significant at 0.05 level
\end{tabular}

and beta $\mathrm{N}$ acetyl hexosaminidase enzymes that lead to bone remodelling by binding to CXCR3, a chemokine receptor produced by endothelial cells and expressed on osteoblasts [37].

The role of CXCL10 as a biomarker in periodontitis has been studied and it was found to be elevated in periodontitis [29, 30, 38, 40] and sometimes decreased in periodontal inflammation [39]. Therefore, the role of CXCL10 in periodontitis needs to be further studied. The influence of smoking on CXCL10 levels also needs further validation.

In the present study, periodontal parameters like pocket probing depth and clinical attachment loss were significantly correlating with CXCL10 levels in both the groups. This suggests that, in periodontitis there was an elevated level of CXCL10. Similar findings were observed by Shimada Y et al [29] in 2012, who observed 40 cytokines and chemokines in GCF of 11 periodontitis subjects and found that CXCL10 levels were elevated in sites with higher bleeding scores.

In a multiplex proximity extension assay Panezai et al [30] analysed 92 cytokines in serum samples of both rheumatoid arthritis subjects and healthy subjects, and observed chemokines like CXCL10 were positively associated with periodontitis.

In addition, Rath-Deschner et al [38] year 2020 found that chemokines like CXCL5, CXCL8 and CXCL10 levels were elevated in inflamed gingival sites compared to healthy sites in both humans and rats.

In the current study, between groups, the CXCL10 marker was found to be higher in smoking subjects with periodontitis which was statistically significant. This finding suggests that, despite similar clinical parameters, smoking influences CXCL10 levels.

Cigarette smoking is a modifiable risk factor and induces PMN respiratory burst and oxidative stress in periodontal tissues. In addition, it induces oxygen depletion in periodontal tissues and alters the response of PMN to periodontal bacteria. Smoking also influences chemokine levels in periodontal disease. Li Nie et al in 2008 observed that CXCL10 levels were elevated in mice exposed to cigarette smoking. Cigarette smoke elevates PMN and chemokines such as CXCL10, CXCL9, CXCL10 binds to receptor CXCR3 and attracts $\mathrm{T}$ lymphocyte at the inflammation site [40]. In CD4 T cells, CXL10 activates the ERK and Akt signalling pathways, which suggests that these signalling pathways may be involved in the RANKL and TNF induction of CXL10 in CD4 $\mathrm{T}$ cells. Kwak et al, 2008 concluded that CXCL10 induces osteoclast differentiation by inducing RANKL in CD4 $\mathrm{T}$ cells in a co-culture of osteoclast precursors and CD4 T cells [25]. In the present study, CXCL10 levels were detected in both the groups, clinical parameters like gingival index, plaque index, pocket probing depth and clinical attachment loss were statistically significant in both the groups. However, CXCL10 levels were elevated in group II compared to group I. Similarly, Souto G R et al [41] evaluated chemokines levels in gingival tissue samples of generalized periodontitis in smokers and non-smokers and observed elevated chemokine levels in smokers. Aldahlawi et al [31] also observed elevated levels of CXCL10 in saliva, serum and GCF of chronic periodontitis compared to gingivitis subjects and CXCL10 levels were elevated in smokers. However, statistical significance could not be obtained due to very less smoker subjects.

Results of the present study indicate that, CXCL10 is elevated in periodontitis and smoking causes elevation of this biomarker by altering PMN response and therefore causing chemokine increase. This exaggerates the periodontal inflammation as evidenced by high CXCL10 levels in this study. Smoking is a modifiable risk factor, and decreasing or modifying this risk can significantly reduce these chemokines. In future, CXCL10 levels before and after phase I nonsurgical therapy in periodontitis subjects might help us to assess if inflammation is related to CXCL10 levels.

There is no literature evidence showing elevated levels of CXCL10 in stage III or IV generalized periodontitis in smokers compared to stage III or IV generalized periodontitis in non-smokers, correlating systemic and local CXCL10 levels with clinical parameters. A larger sample size and duration of smoking status could have improved the results of the present study. 


\section{Acknowledgement}

SRM Dental College, Ramapuram, Chennai for providing the study participants.

\section{References}

[1]. Wolff L, Dahlén G, Aeppli D. Bacteria as risk markers for periodontitis. J. Periodontol. 1994 May;65:498-510.

[2]. DeStefano F, Anda RF, Kahn HS, Williamson DF, Russell CM. Dental disease and risk of coronary heart disease and mortality. Br Med J. 1993 Mar 13;306(6879):688-91.

[3]. Bullon P, Newman HN, Battino M. Obesity, diabetes mellitus, atherosclerosis and chronic periodontitis: a shared pathology via oxidative stress and mitochondrial dysfunction? Periodontol 2000. 2014 Feb;64(1):139-53.Pubmed PMID: 24320961.

[4]. Johannsen A, Susin C, Gustafsson A. Smoking and inflammation: evidence for a synergistic role in chronic disease. Periodontol 2000. 2014 Feb;64(1):111-26.

[5]. Warren KR, Postolache TT, Groer ME, Pinjari O, Kelly DL, Reynolds MA. Role of chronic stress and depression in periodontal diseases. Periodontol 2000. $2014 \mathrm{Feb} ; 64(1): 127-38$.

[6]. Dunford RG, Lyon E, Ho AW, Machtei EE, Christersson LA, Grossi SG, et al. Smoking as a significant risk indicator for severe adult periodontal disease. J Dent Res. 1991;70:590.

[7]. Krall EA, Dawson-Hughes B, Garvey AJ, Garcia RI. Smoking, smoking cessation, and tooth loss. J Dent Res. 1997 Oct;76(10):1653-9.

[8]. Krall Kaye E, Dietrich T, Nunn ME, Garcia RI. Risk of Tooth Loss After Cigarette Smoking Cessation. Prev Chronic Dis. 2006;3:A115.

[9]. Preshaw PM, Heasman L, Stacey F, Steen N, McCracken GI, Heasman PA. The effect of quitting smoking on chronic periodontitis. J Clin Periodontol. 2005 Aug;32(8):869-79.

[10]. Mason MR, Preshaw PM, Nagaraja HN, Dabdoub SM, Rahman A, Kumar PS. The subgingival microbiome of clinically healthy current and never smokers. ISME J. 2015 Jan;9(1):268-72.Pubmed PMID: 25012901.

[11]. Boström L, Linder LE, Bergström J. Clinical expression of TNF-alpha in smoking-associated periodontal disease. J Clin Periodontol. 1998 Oct;25(10):767-73.Pubmed PMID: 9797047.

[12]. Söder B. Neutrophil elastase activity, levels of prostaglandin E2, and matrix metalloproteinase- 8 in refractory periodontitis sites in smokers and non-smokers. Acta Odontol Scand. 1999 Apr;57(2):77-82.Pubmed PMID: 10445359.

[13]. Silva TA, Garlet GP, Lara VS, Martins Jr W, Silva JS, Cunha FQ. Differential expression of chemokines and chemokine receptors in inflammatory periapical diseases. Oral Microbiol Immunol . 2005 Oct;20(5):310-6.

[14]. Ohmori Y, Hamilton TA. The interferon-stimulated response element and a kappa $B$ site mediate synergistic induction of murine IP-10 gene transcription by IFN-gamma and TNF-alpha. J Immunol. 1995 May 15;154(10):523544.Pubmed PMID: 7730628

[15]. Dillman JF 3rd, McGary KL, Schlager JJ. An inhibitor of p38 MAP kinase downregulates cytokine release induced by sulfur mustard exposure in human epidermal keratinocytes. Toxicol In Vitro. 2004 Oct;18(5):593-9. Pubmed PMID: 15251176

[16]. Ohmori Y, Hamilton TA. Cell type and stimulus specific regulation of chemokine gene expression. Biochem. Biophys. Res. Commun. 1994 Jan 31;198(2):590-6

[17]. Shields PL, Morland CM, Salmon M, Qin S, Hubscher SG, Adams DH. Chemokine and chemokine receptor interactions provide a mechanism for selective $\mathrm{T}$ cell recruitment to specific liver compartments within hepatitis C-infected liver. J Immunol. 1999 Dec 1;163(11):6236-43.Pubmed PMID: 10570316.

[18]. Ciesielski CJ, Andreakos E, Foxwell BM, Feldmann M. TNFalpha-induced macrophage chemokine secretion is more dependent on NF-kappaB expression than lipopolysaccharides-induced macrophage chemokine secretion. Eur J Immunol. 2002 Jul;32(7):2037-45.Pubmed PMID: 12115625.

[19]. Bach EA, Aguet M, Schreiber RD. The IFN $\gamma$ receptor: a paradigm for cytokine receptor signaling. Annu Rev Immunol . 1997 Apr;15(1):563-91

[20]. Angiolillo AL, Sgadari C, Taub DD, Liao F, Farber JM, Maheshwari S, et al. Human interferon-inducible protein 10 is a potent inhibitor of angiogenesis in vivo. J Exp Med. 1995 Jul 1;182(1):155-62.

[21]. Luster AD, Unkeless JC, Ravetch JV. Gamma-interferon transcriptionally regulates an early-response gene containing homology to platelet proteins.
Nature. 1985 Jun 20-26;315(6021):672-6.Pubmed PMID: 3925348.

[22]. Groom JR, Luster AD. CXCR3 ligands: redundant, collaborative and antagonistic functions. Immunol Cell Biol. 2011 Feb;89(2):10.Pubmed PMID: 21221121.

[23]. Altara R, Gu YM, Struijker-Boudier HA, Thijs L, Staessen JA, Blankesteijn WM. Left Ventricular Dysfunction and CXCR3 Ligands in Hypertension: From Animal Experiments to a Population-Based Pilot Study. PLoS One. 2015 Oct 27;10(10):e0141394.Pubmed PMID: 26506526.

[24]. Altara R, Manca M, Hessel MH, Gu Y, van Vark LC, Akkerhuis KM, et al. CXCL10 Is a Circulating Inflammatory Marker in Patients with Advanced Heart Failure: a Pilot Study. J Cardiovasc Transl Res. 2016 Aug;9(4):302-14. Pubmed PMID: 27271043.

[25]. Kwak HB, Ha H, Kim HN, Lee JH, Kim HS, Lee S, et al. Reciprocal cross-talk between RANKL and interferon-gamma-inducible protein 10 is responsible for bone-erosive experimental arthritis. Arthritis Rheum. 2008 May;58(5):1332-42.Pubmed PMID: 18438854

[26]. Lee JH, Kim B, Jin WJ, Kim HH, Ha H, Lee ZH. Pathogenic roles of CXCL10 signaling through CXCR3 and TLR4 in macrophages and T cells: relevance for arthritis. Arthritis Res Ther. 2017 Jul 19;19(1):163.Pubmed PMID: 28724396.

[27]. Hanaoka R, Kasama T, Muramatsu M, Yajima N, Shiozawa F, Miwa Y, et al. A novel mechanism for the regulation of IFN-gamma inducible protein-10 expression in rheumatoid arthritis. Arthritis Res Ther. 2003;5(2):R74-81. Pubmed PMID: 12718750.

[28]. Green EB. The Role of CXCL9 and CXCL10 in Periodontal Bone Loss. University of California, Los Angeles. 2018.

[29]. Shimada Y, Tabeta K, Sugita N, Yoshie H. Profiling biomarkers in gingival crevicular fluid using multiplex bead immunoassay. Arch Oral Biol. 2013 Jun 1;58(6):724-30

[30]. Panezai J, Ghaffar A, Altamash M, Sundqvist KG, Engström PE, Larsson A. Correlation of serum cytokines, chemokines, growth factors and enzymes with periodontal disease parameters. PloS one. 2017 Nov 30;12(11):e0188945.

[31]. Aldahlawi S, Youssef AR, Shahabuddin S. Evaluation of chemokine CXCL10 in human gingival crevicular fluid, saliva, and serum as periodontitis biomarker. J Inflamm Res. 2018 Oct 31;11:389-396.Pubmed PMID: 30464571.

[32]. SILNESS J, LOE H. PERIODONTAL DISEASE IN PREGNANCY. II CORRELATION BETWEEN ORAL HYGIENE AND PERIODONTAL CONDTION. Acta Odontol Scand. 1964 Feb;22:121-35.Pubmed PMID: 14158464.

[33]. Löe $H$. The gingival index, the plaque index and the retention index systems. J Periodontol. 1967 Nov;38(6):610-6.

[34]. Caton JG, Armitage G, Berglundh T, Chapple IL, Jepsen S, Kornman KS, et al. A new classification scheme for periodontal and peri-implant diseases and conditions-Introduction and key changes from the 1999 classification. J Periodontol. 2018 Jun;89:S1-8.

[35]. Navazesh M. Methods for collecting saliva. Ann. N. Y. Acad. Sci.. 1993 Sep;694:72-7.

[36]. Grassi F, Piacentini A, Cristino S, Toneguzzi S, Cavallo C, Facchini A, et al. Human osteoclasts express different CXC chemokines depending on cell culture substrate: molecular and immunocytochemical evidence of high levels of CXCL10 and CXCL12. Histochem Cell Biol. 2003 Nov;120(5):391400.Pubmed PMID: 14600836.

[37]. Lisignoli G, Toneguzzi S, Piacentini A, Cattini L, Lenti A, Tschon M, et al. Human osteoblasts express functional $\mathrm{CXC}$ chemokine receptors 3 and 5 : activation by their ligands, CXCL10 and CXCL13, significantly induces alkaline phosphatase and beta-N-acetylhexosaminidase release. J Cell Physiol. 2003 Jan;194(1):71-9.Pubmed PMID: 12447991.

[38]. Rath-Deschner B, Memmert S, Damanaki A, de Molon RS, Nokhbehsaim M, Eick S, et al. CXCL5, CXCL8, and CXCL10 regulation by bacteria and mechanical forces in periodontium. Ann Anat. 2020 Mar;234:151648.Pubmed PMID: 33221386

[39]. Tymkiw KD, Thunell DH, Johnson GK, Joly S, Burnell KK, Cavanaugh JE, et al. Influence of smoking on gingival crevicular fluid cytokines in severe chronic periodontitis. J Clin Periodontol . 2011 Mar;38(3):219-28.

[40]. Nie L, Xiang R, Zhou W, Lu B, Cheng D, Gao J. Attenuation of acute lung inflammation induced by cigarette smoke in CXCR3 knockout mice. Respir. Res. 2008 Dec;9(1):1-0.

[41]. Souto GR, Queiroz-Junior CM, Costa FO, Mesquita RA. Smoking effect on chemokines of the human chronic periodontitis. Immunobiology. 2014 Aug 1;219(8):633-6. 